\title{
Imaginarios sociales de infancia y su incidencia en la práctica pedagógica de una escuela bogotana ${ }^{1}$
}

\author{
Social imaginaries of childhood and its effects in the pedagogical practice of a \\ school in Bogotá
}

Imaginários sociais da infância e sua incidência na prática pedagógica de
uma escola bogotana

Ana Virginia Triviño R. ${ }^{2}$

Universidad Distrital Francisco José de Caldas, Colombia

Recepción: 12/05/2018

Evaluación: 08/06/2018

Aceptación: 29/06/2018

Artículo de Investigación

DOI: 10.19053/01227238.8538:

\section{RESUMEN}

El presente artículo da cuenta de los desarrollos teóricos y metodológicos, así como de algunos hallazgos en torno a la categoría infancia perteneciente a la investigación titulada "Los imaginarios sociales de infancia, niño, niña y joven y la práctica pedagógica en la escuela del Distrito Capital", desarrollada en el colegio Santa Librada IED, la cual parte de preguntarse por ¿Cuáles son los imaginarios sociales de niño, niña y joven que subyacen en la práctica pedagógica de los maestros y maestras de la escuela bogotana, y si es posible identificar su modificación desde una propuesta pedagógica institucional?

El estudio se sitúa en el campo de los imaginarios sociales y la práctica pedagógica, estableciendo un tejido entre la historia de los sujetos, el discurso y sus prácticas, a partir de ese magma de significaciones que los maestros y maestras construyen en torno a la infancia. Asume a la escuela como un espacio social donde coexisten un sinnúmero de sentidos y significados que, entre pasado, presente y futuro, instituyen las formas de educar a los niños y niñas. Metodológicamente, teniendo en cuenta que los imaginarios sociales son elaboraciones que se producen y develan en y por el lenguaje, el estudio se ubica en los enfoques cualitativos interpretativos, recurriendo al uso de técnicas de investigación como la entrevista, los relatos y la observación, con lo cual se buscó recoger información que permitiera develar las significaciones imaginarias que los maestros tienen sobre los niños y

$1 \quad$ El artículo presenta algunos resultados de la investigación titulada "Imaginarios sociales de infancia, niño, niña y joven y la práctica pedagógica en la escuela del Distrito Capital”, desarrollada en el Colegio Santa Librada IED para optar al título de maestría en Investigación Social Interdisciplinaria de la Universidad Distrital Francisco José de Caldas, realizada entre 2006 y 2007, terminada en abril de 2008. Financiada por la Secretaría de Educación del Distrito. ORCid. https://orcid.org/0000-0002-5257-938X.

2 Magíster en Investigación Social Interdisciplinaria, Universidad Distrital Francisco José de Caldas. Docente - Investigadora de la Universidad Distrital Francisco José de Caldas. Investigadora del Grupo de Investigación infancias. Docente de la Secretaría de Educación del Distrito. Correo electronico: virgitri@gmail.com 
niñas y cómo, desde estas, dan sentido y orientan su práctica pedagógica.

Palabras clave: Imaginarios sociales; instituido e instituyente; infancia; práctica pedagógica; Revista Historia de la Educación Latinoamericana.

\footnotetext{
ABSTRACT

This article presents some theoretical and methodological advances, as well as some findings around the childhood category belonging to the research work entitled "The social imaginaries of childhood, boy, girl, and young people and the pedagogical practice in the Capital District's school ", which was carried out at the Santa Librada IED school. The starting question of the research is about the social imaginaries of boys, girls and young people that underlie the pedagogical practice of the school teachers in Bogotá, and whether it is possible to identify their modification from an institutional pedagogical proposal.

The study belongs to the field of social imaginaries and pedagogical practices, it establishes a connection between the history of the subjects, their discourse, and their practices, based on that magma of meanings that teachers build up around childhood. The school is assumed as a social space where countless senses and meanings model the ways of educating children in the coexistence of past, present, and future.

Taking into account that social imaginaries are elaborations produced and unveiled in and by language, the methodology of this study is located in interpretive approaches. Research techniques such as interviews, stories, and observation were used to collect information that would allow us to reveal the imaginaries of teachers about children and their effect on the meaning of their pedagogical practice. Keywords: Social imaginaries; the Instituting and the Instituted; childhood pedagogical practice; Journal History of Latin American Education.
}

RESUMO
O presente artigo aborda os desenvolvimentos teóricos e metodológicos, assim como de algumas descobertas em torno da categoria infância pertencente à pesquisa intitulada "Los imaginários sociais de infância, menino, menina e jovem e a prática pedagógica na escola do Distrito Capital", desenvolvida no colégio Santa Librada IED, a qual parte da pergunta: quais são os imaginários sociais de menino, menina e jovem que subjazem a prática pedagógica dos professores e professoras da escola bogotana, e se é possível identificar sua modificação desde uma proposta pedagógica institucional? O estudo se situa no campo dos imaginários sociais e a prática pedagógica, estabelecendo um tecido entre a história dos sujeitos e suas práticas, a partir desse magma de significações que os professores constroem em torno da infância. Assume a escola como um espaço social onde coexiste um sem número de sentidos e significados que, entre passado, presente e futuro, instituem as formas de educar os meninos e as meninas. Metodologicamente, tendo em conta que os imaginários sociais são elaborações que se produzem e desvelam na e pela linguagem, o estudo se localiza nos enfoques qualitativos interpretativos, recorrendo ao uso das técnicas de pesquisa com a entrevista, os relatos e a observação, com o qual se buscou recolher informação que permitiu desvelar as significações imaginárias que os professores têm sobre os meninos e meninas e como, desde estas, dão sentido e orientam sua prática pedagógica.

Palavras-chave: Imaginários sociais; instituído e instituinte; infância; prática pedagógica; Revista História da Educação Latino-americana. 


\section{INTRODUCCIÓN}

Este estudio constituye su objeto de investigación en el "ser de la sociedad", es decir, en las formas de significar a los sujetos, las relaciones de comunicación y las formas simbólicas de la cultura que crean sentido y significación. Es a partir de estos elementos que se establece un tejido que orienta la vida de un grupo humano, que instaura formas de relaciones y necesidades particulares a cada uno de los sujetos, en este caso de infantes y maestros, quienes en el marco de ese colectivo anónimo instituyen un mundo propio a partir de crear un sistema de interpretación de la realidad.

La investigación ubica los imaginarios sociales sobre infancia, niño y niña en el campo de la educación, lo pedagógico, lo social y lo histórico de una sociedad como la colombiana y un grupo social, los maestros y maestras de una escuela bogotana, preguntándose por ¿cuáles son los imaginarios sociales sobre infancia que tienen los maestros?, ¿cuáles de estos imaginarios son instituidos e instituyentes?, y ¿cómo estos orientan la práctica pedagógica?, pero también se preguntó por el sentido y significado que los maestros dan a su práctica pedagógica y si es posible que, al relacionarse con una propuesta pedagógica institucional, dichos sentido y significado puedan ser modificados en procura de mejorar la interacción pedagógica y así mismo la calidad de la educación.

El contexto de la investigación es el colegio Santa Librada I. E. D., institución educativa adscrita a la Secretaría de Educación de Bogotá que ofrece los niveles de educación Preescolar, Básica y Media en las dos jornadas a niños y jóvenes de estratos 1 y 2 de la localidad 5 de Usme. Es una institución que cuenta con más de 60 años de existencia. Desde el año 2001 propone como énfasis del Proyecto Educativo Institucional (PEI), la comunicación y los valores y define como modelo y estrategia pedagógica el aprendizaje significativo, con el cual se ha pretendido orientar el quehacer docente en el aula.

En este sentido es que la pregunta por los imaginarios sociales de infancia, niño y niña ${ }^{3}$ que tienen los maestros y con los cuales orientan su práctica pedagógica, cobra relevancia por cuanto es desde ese magma de significaciones que configuran los imaginarios instituidos, instituyentes e institucionalizados, los cuales caracterizan el decir/representar y el hacer/representar de los colectivos de maestros, que se establece un tejido que orienta la vida de un grupo humano, que instaura formas de relaciones y necesidades particulares de cada uno de los sujetos, en este caso de los niños, las niñas y los maestros, quienes en el marco de ese colectivo anónimo instituyen un mundo para sí a partir de crear un sistema de interpretación de la realidad. De igual forma indagar por los imaginarios sociales de los maestros y su práctica pedagógica permite evidenciar algunos elementos de transformación al interactuar con la propuesta pedagógica institucional.

3 Es necesario aclarar que, para este artículo, solo se retoma la categoría infancia, niño y niña, de la investigación "Los imaginarios sociales de infancia, niño, niña y joven y la práctica pedagógica en la escuela del Distrito Capital, 2008”. 


\section{Los imaginarios sociales: una teoría y un concepto para comprender el mundo social $^{4}$}

El estudio asume los imaginarios desde la perspectiva sociológica e histórica, donde los imaginarios sociales son un magma de significaciones (representaciones, afectos, deseos, sentimientos y actuaciones) que constituyen un conjunto real de imágenes con las cuales los sujetos construyen, dan sentido al mundo en su relación permanente y dialógica con el colectivo anónimo.

Este conjunto de representaciones e imágenes se nutre de las diferentes formas de la vida social y se encarna en las prácticas sociales. Considerando la constitución de los imaginarios en su doble papel, como referencia interpretativa del mundo de los sujetos y como constitutivos y formadores en el proceso de institucionalización de una sociedad, los imaginarios sociales son la fuerza creadora de la sociedad.

Según la perspectiva sociológica de los imaginarios sociales de Cornelius Castoriadis ${ }^{5}$, estos son fuerza creadora del mundo social que, desde un sistema de creencias, saberes y prácticas expresadas a través de representaciones, deseos, afectos y actuaciones, forman las significaciones imaginarias sociales con las cuales se asegura la cohesión y el consenso del colectivo anónimo y se instituye la existencia de la sociedad en un tiempo determinado.

Así, lo imaginario social es la creación de significaciones, de imágenes o figuras que les sirven de soporte y dotan de sentido lo real y las prácticas. "Lo imaginario de lo que hablo no es imagen de. Es creación incesante, y esencialmente indeterminada (social-histórico y psíquico) de figuras / formas / imágenes, a partir de las cuales solamente puede tratarse de 'alguna cosa'. Lo que llamamos «realidad»y «racionalidad» son obras de ello"6.

Esto nos lleva a pensar que la realidad que establece un grupo social, lo que define y orienta sus actuaciones, está construida a partir de esa red de representaciones, sentimientos y deseos que son legitimados al ser compartidos y que por sus características son irreductibles al sistema racional y trascienden al mundo del inconsciente o la psique. Por lo tanto, los imaginarios sociales de infancia son un conjunto complejo de imágenes, representaciones y sentires que, en el contexto de la escuela o institución educativa, emplean todo tipo de producciones sociales para sobrevivir, como las creencias, la memoria, el cuerpo, los gestos y las prácticas que se arraigan y se resisten a los cambios en tiempos determina-

$4 \quad$ Realizar una apuesta teórica desde los estudios imaginarios sociales sobre la infancia implicó develar que estos estudios toman relativa fuerza en Colombia en la última década y que sus perspectivas van desde lo imaginario como campo de la historia y la sociológica, hasta lo imaginario como campo de la psicología. Como referencia se pueden citar los estudios de Elsa María Bocanegra Acosta, "Del encierro al paraíso. Imaginarios dominantes en la escuela colombiana contemporánea: una mirada desde las escuelas de Bogotá", Revista Latinoamericana de Ciencias Sociales, Niñez y Juventud, 6, n. ${ }^{\circ} 1$ (enero-junio 2008): 319-346; Doris Liliana Torres Cruz, "El papel de la escuela en la construcción de la nacionalidad. Una aproximación a la escuela elemental, 1900 a 1930", Revista Historia de la Educación Latinoamericana, n. 13 (2009): 213-240; Diana Elvira Soto Arango, "Legislación e imaginarios sociales en el escalafón y los salarios de los educadores de primaria en Colombia, 1952-1994", Revista Historia de la Educación Latinoamericana, vol.15, n. 21 (2013): 229-262; Nancy Palacios Mena, "Transformación y crisis de la escuela: algunas reflexiones sobre el caso colombiano" Revista Historia de la Educación Latinoamericana, vol.15, n. ${ }^{\circ} 1$ (2013): 335-376.

5 Cornelius Castoriadis, La institución imaginaria de la sociedad (Francia: Editorial Senil, 1975).

6 Ibíd., 252. 
dos, pero que, como construcciones culturales e históricas, se pueden modificar en el entramado complejo del mundo social escolar.

Entonces, la indagación por los imaginarios de infancia, sus permanencias, ausencias, desplazamientos y rupturas, considera ese flujo dinámico de creaciones, incesante e indeterminado, que tiene lugar en la escuela; a partir de la historia de vida de los maestros, su formación profesional, su experiencia pedagógica como parte del mundo psíquico y que se relaciona en ese escenario cultural con las construcciones y propuestas institucionales, instancias sustanciales para la "construcción de la realidad" y para la comprensión de las relaciones entre los discursos y las prácticas.

Esta relación de elementos que componen un conjunto de significaciones, estableciéndose que los imaginarios se nutren de toda clase de producciones sociales, a través de las cuales se constituye la sociedad y que le dan la dinámica de cambio pues puede ponerla en conflicto, por lo tanto, se considera que los imaginarios funcionan durante cierto tiempo, pueden reaparecer en un momento determinado, y existen en una época determinada y se pueden transformar en una multiplicidad de tiempos.

Las imágenes que componen un imaginario pueden cambiar en espacios cortos de tiempo y, en los procesos de interacción, modificar actitudes arraigadas, asumiendo los imaginarios como una red de imágenes, pero también como una estructura de cognición. Por lo tanto, se estudia un grupo humano de maestras y maestros desde su producción cultural, ocupándose más por las significaciones e interacciones entre sujetos. Esta concepción resulta pertinente, en cuanto permite establecer la articulación entre ideas y prácticas pedagógicas, conceptos, narraciones e imaginarios relativos a la infancia, el niño y la niña a través de la práctica docente de maestros y maestras.

Se considera además que es ese conjunto de significaciones simbólicas lo que estructura en cada instante la experiencia social y engendra comportamientos, imágenes, actitudes y sentimientos que movilizan acciones de los sujetos. Esto nos lleva a pensar que lo "creíble" en un grupo social, lo que motiva y orienta las actuaciones, está determinado por sistemas de significación socialmente legitimados. Así, los imaginarios se definen como ese magma de significaciones imaginarias sociales, locales e indefinibles, y a veces arbitrarias, que componen la "institución de la sociedad".

Al estudiar ese magma de significaciones que constituyen los imaginarios es posible develar la estructura inteligible de toda actividad humana que otorga sentido a la acción social, que reglamenta, institucionaliza y legitima ciertas formas de decir y hacer. Es decir, la acción o el mundo social se producen a través de la red de sentido por medio de la cual los miembros de una colectividad se comunican, establecen identidad y designan sus formas de relación. En este caso, los maestros y maestras, creando imágenes, afectos, representaciones y sentidos de sí mismos y de los otros (niños y niñas), elaboran un orden social y unas formas de relación a partir de las cuales, en un espacio como la escuela, 
distribuyen los roles, las funciones, y crean rituales que consolidan un orden institucional compartido que se devela en las prácticas y la acción pedagógicas.

Se puede entonces afirmar que, a partir de la relación psiquis/sociedad, los imaginarios sociales son elaboraciones colectivas donde se conjugan el universo simbólico, lo real, los afectos, los sentidos y las acciones con las cuales los seres humanos construimos mundos propios que tienen como finalidad la existencia y la protección, mundos simbólicos que se hacen evidentes en el mundo del lenguaje.

Los imaginarios sociales descansan sobre el fundamento de la cultura como producto del mundo simbólico que deviene de la necesidad originaria de trascender lo biológico y se convierte en un magma de diversidad en constante movimiento; por lo tanto, "lo imaginario juega un papel fundamental en los procesos de legitimación y trasgresión del orden social" ${ }^{\prime 7}$. Esta dimensión de la conformación de los imaginarios sociales se plasma en la emergencia de una subjetividad social, donde lo racional y lo objetivo se apoyan sobre un frágil pilar inconsciente, develando la doble dimensión de la naturaleza humana.

Así, los estudios sobre imaginarios sociales de infancia han coadyuvado a la construcción de un discurso histórico social, han instalado otras formas de comprender las dinámicas escolares, haciendo emerger una multiplicidad de centros de significación que se arraigan en las subjetividades de los maestros y sus prácticas, afirmando la existencia del sujeto maestro como productor de conocimiento y de identidad del colectivo, desde donde aporta para transformar lo instituido en la escuela y la sociedad.

En este sentido es que las instituciones educativas deben mirar la infancia no solo en sus condiciones materiales de existencia, el "aquí y ahora", sino en su proceso de constitución histórica social, en sus formas de relación con el mundo del adulto y las formas como han sido significadas hasta convertirlas en actores/ sujetos sociales, en cuanto que es desde estas construcciones que se predisponen comportamientos, actuaciones, relaciones y hasta las aspiraciones que los maestros como grupo social construimos en torno a los niños y las niñas, así como son estas significaciones que definen de una $u$ otra manera las condiciones de existencia, de aprendizaje, las oportunidades y la vida académica de los niños.

Así, el estudio considera la práctica pedagógica orientada, entre otras, por las ideas-imágenes con las cuales piensan, creen, sueñan y se representan a los niños. Estas significaciones imaginarias sociales constitutivas de la psique de los maestros y del ser colectivo de la escuela, se develan como el decir/representar y hacer/representar, constituido desde la experiencia de los sujetos, y se nutre de todas las formas, discursos y saberes que ponen en juego en los procesos de socialización a través de la tradición y de la creencia, con lo cual se instaura un imaginario que comparte con sus congéneres un imaginario instituido.

Así mismo, esta investigación consideró que la práctica pedagógica se encuentra inmersa en una propuesta pedagógica institucional que promueve una

7 Ángel E. Carretero, "Postmodernidad e imaginario. Una aproximación teórica", A Parte Rei, n. ${ }^{\circ}$ 21, acceso en marzo de 2016, serbal. pntic.mec.es/ cmunoz11/carretero26.pdf. 
idea, una imagen o un concepto de niño, niña, como sujeto pedagógico, es decir, un imaginario institucionalizado que, al entrar en juego con los imaginarios instituidos que tienen los maestros desde su experiencia y formación, tejen esa amalgama de significaciones sociales, dialéctica en la cual se mueven las construcciones sociales donde se pueden alterar, reconfigurar y hacer emerger nuevas redes de significaciones que dan paso a la creación de imaginarios instituyentes en el marco de una acción pedagógica, como acción social.

Para la investigación, lo instituido y lo institucionalizado son ese grupo de significaciones, sentidos y símbolos estables, definidos y anclados, que terminan por definir un sistema de interpretaciones presentes en la cultura y que permiten la adhesión a un sistema de valores que intervienen eficazmente en el proceso interiorización, moldeado de conductas, de socialización, y determinan la existencia y el accionar de los sujetos en el marco de lo social.

Lo instituido se construye sobre la experiencia de los maestros, sobres sus deseos, aspiraciones e intereses. Con ello se asegura un esquema colectivo de interpretación para el quehacer individual en el aula de clase, desde donde se construye la memoria institucional y las representaciones con las cuales los maestros se relacionan con la infancia. Este sistema de interpretación establece unas condiciones como son la organización del tiempo colectivo en la escuela y la instalación de ritos y rutinas en la vida cotidiana de los niños y niñas.

De modo que la escuela, como institución de la sociedad, es portadora de esas significaciones socialmente compartidas y es considerada como el espacio secundario de socialización, en donde los sujetos (niños, niñas y maestros) asumen las instituciones, además de las significaciones que consolidan el imaginario instituido. En relación con las formas de pensar y representar los niños y las niñas, a partir de las prácticas pedagógicas de los maestros la escuela consolida unas concepciones y significaciones de los niños en un ámbito pedagógico.

Infancia, niñez, niño, niña y joven son categorías creadas bajo parámetros que han sido instituidos socialmente, no solo como representación sino como la capacidad de desplazamiento de sentido que se institucionaliza en una sociedad mediante procesos de aceptación colectiva. Estas categorías dan cuenta de la existencia real de niños, niñas y jóvenes a partir de conformarse en significaciones imaginarias sociales desde las cuales los sujetos de una sociedad los explican, los comprenden y se relacionan con ellos.

De otra parte, el imaginario social instituyente tiene como fuente de creación el deseo que se concreta en la imaginación, a partir de la cual surgen representaciones, que si bien son individuales, al ser compartidas con otros generan transgresiones, discontinuidades y rupturas, propiciando así un espacio de construcción colectiva humana. Como lo señala Baczko ${ }^{8}$, para conservar la cultura a través de la historia las sociedades han inventado dispositivos que van de la protección a la represión, dispositivos que no son más que significaciones imaginarias que

8 Bronislaw Baczko, Los imaginarios sociales. Memorias y esperanzas colectivas (Buenos Aires: Editorial Nueva Visión, 1991), 29. 
emergen para competir con lo instaurado, y dejan a la sociedad en crisis hasta cuando logra legitimarse y así asegurar cambios.

Lo instituyente establece un proceso de alteración social, donde los imaginarios sociales plantean un tejido entre lo individual y lo colectivo, lo semejante y lo diferente, construyendo un magma de significaciones que se refieren a situaciones, a los otros y a las cosas, que no se pueden reducir y tampoco disociar, por lo que son las claves para poder incidir en la transformación de las prácticas pedagógicas, las realidades escolares, las formas de relación con los niños, las formas de trato e inclusive sus prospectivas de vida, en donde lo instituyente va más allá de lo posible y de lo real.

Así, lo instituyente comporta un potencial que le permite la creación de universos de sentido, por lo tanto, cuando se afirma que la escuela está en crisis, en el fondo lo que se puede estar diciendo es que están surgiendo nuevas formas de decir y hacer frente a las necesidades fundamentales de los niños y los maestros y de la escuela misma como institución de la sociedad, en donde emergen nuevas significaciones que quieren legitimidad, reconocimiento y ser instituidas, es decir, compartidas por el colectivo. Y es aquí, en esta lucha, en este entretejido de significados, que este estudio ve la posibilidad de la transformación de las prácticas pedagógicas, en donde la propuesta de nuevas significaciones sobre la infancia que deviene de la apuesta pedagógica y curricular, se entrecruza con las significaciones que tienen maestras y maestros desde su historia personal, pero también con aquellas que se han reconfigurado a partir de su proceso de formación y experiencia; dándose entonces desplazamientos y emergencia de nuevas formas de significar la infancia y para esa infancia otras prácticas, otras relaciones, otras condiciones de existencia de los niños y las niñas en la escuela. Entonces:

La sociedad se constituye y autoaltera con el flujo de las significaciones imaginarias que crea para organizarse y dotarse de un mundo, que tiende a la clausura (aunque nunca se cierra), en el que ella encuentra sentido e identidad. Ese mundo se crea a través de instituciones. La institución es la creación de sistemas simbóli$\cos ($...) sancionados que establecen la regulación normativa, funciones y formas de pensar, representar, ser y actuar, que regulan las relaciones y las prácticas sociales ${ }^{9}$.

En este proceso la escuela es un espacio instituyente pues, como institución de la sociedad en la que se instalan todos los imaginarios instituidos, es un espacio de creación y resignificación de lo instituido, para convertirse en instituyente. En su propuesta pedagógica porta un imaginario institucionalizado e instituido, pues se instaura en un ámbito de poder y política educativa, sin embargo, en algunas ocasiones, la escuela deja de ser solo el ámbito de reproducción de la sociedad y desde su acción pedagógica y su quehacer, enmarcado en los procesos de enseñanza y aprendizaje, resignifica estos imaginarios haciéndolos creadores

9 Raúl Enrique Anzaldúa Arce, “Lo imaginario como significación y sentido”, en Imaginario social: creación de sentido, coord. por Raúl Enrique Anzaldúa Arce (México: Universidad Pedagógica Nacional, 2012), 32. 
de nuevas formas de relación, que son institucionalizados a través del PEı y sus rituales y se vuelven instituidos en el momento en que son compartidos por toda la comunidad educativa.

\section{Consideraciones metodológicas}

Teniendo en cuenta que los imaginarios sociales son elaboraciones hechas a partir del universo simbólico de los sujetos y los colectivos y que requieren para su existencia el mundo del lenguaje desde el cual crea múltiples significaciones que circulan en una comunidad, como son los maestros, este estudio convoca una metodología desde los enfoques cualitativos-interpretativos. Un enfoque que permite realizar una comprensión en el orden de la intersubjetividad y develar desde ella tanto lo singular como lo colectivo, desde donde se otorga sentido a la existencia de los niños en el contexto escolar, como institución social encargada de la formación y en donde el proceso de investigación está mediado por la relación sujeto-sujeto, siendo el sujeto investigador un observador participante de una realidad ${ }^{10}$.

Emplear un enfoque cualitativo permite ver el sentido, es decir, comprender en el orden de la intersubjetividad y a partir de esta develar la singularidad, lo que implica cognición en la diversidad del contexto, lo que faculta realizar un estudio sobre los imaginarios, ya que estos se tejen en la relación de la psiquis y lo colectivo en un contexto cultural, social e histórico determinado y emergen en el discurso y la acción.

Desde este enfoque, evidenciar los imaginarios sociales de los maestros y maestras en sus discursos y tomar las acciones como textos o discursos que pueden ser leídos, permite develar la relación entre los imaginarios instituidos, instituyentes e institucionalizados, dinámica en la que se construyen los imaginarios sociales de los maestros en un contexto que es institución de la sociedad, "la escuela", que se institucionaliza en un contexto cultural lleno de significaciones sociales como la cultura colombiana. Por lo tanto, en esta relación, la interpretación se establece en un momento comprensivo, orientado a que la escuela y sus maestros interpreten y comprendan lo que hacen.

Lo cualitativo-interpretativo permite describir y reconstruir analíticamente los imaginarios sociales sobre la infancia, niño y niña, desde la información discursiva, los escenarios, acciones y procesos de las prácticas pedagógicas de los actores comprometidos. Por lo tanto, las técnicas de recolección de información son variadas y tienen aquí una doble función: recoger información y generar procesos de metacognición que permitan enfatizar en las interpretaciones del quehacer docente, desde sus construcciones individuales (historia de vida, formación y experiencia) y desde los procesos sociales que han construido una cotidianidad a partir de la convivencia en el contexto de la escuela. Las técnicas e

$\overline{10}$ Es necesario aclarar que la investigadora hace parte del grupo de docentes de la institución, a la cual está vinculada hace aproximadamente veinte años. 
instrumentos de recolección utilizadas fueron: una entrevista estructurada, la carta asociativa $^{11}$, una entrevista a profundidad que fue el instrumento del relato corto de vida, observaciones de clase y grupos de discusión de los maestros y maestras.

La sistematización partió del sistema conceptual que determinó algunas categorías y unidades de análisis, que a su vez permitieron agrupar la información en rejillas de análisis para leerla, y encontrar lo común, lo continuo y lo discontinuo en los discursos. Para cada instrumento se construyó una rejilla en la cual se agrupó la producción discursiva en unidades de análisis que tuvo en cuenta el concepto de significaciones imaginarias como constituyente de los imaginarios sociales. Entendidas como la totalidad de lo que puede ser representado, al igual que son creaciones libres entre el sujeto y la sociedad, además de que se consideran el cemento de la vida porque mantienen unidas las ideas, las imágenes, las representaciones y los actos en donde se pueden encontrar las intenciones y los afectos que posibilitan las relaciones sociales.

Desde esta perspectiva se construyeron unidades de análisis desde las cuales se podían develar las significaciones imaginarias, como: historia personal, asociaciones verbales, imágenes de, ideas y conceptos, vínculo con la profesión, asociaciones de infancia con la labor pedagógica, relaciones y actitudes con los niños, niñas y jóvenes, formas de comunicación, sentidos y significados construidos por los maestros y sentidos y significados desde la práctica pedagógica.

A estas unidades de análisis corresponden unas categorías de análisis, como se dijo, determinadas por el sistema conceptual y los objetivos de este estudio, como son: el imaginario instituyente y el imaginario instituido, como categorías gruesas y como categorías de relación e integración entre las representaciones sociales, ideas, concepciones, asociaciones verbales de los maestros en relación con la infancia, los niños y las niñas, y de otro lado, la práctica pedagógica o la relación pedagógica. Todo lo cual permitirá analizar e interpretar de acuerdo con el análisis del discurso como una herramienta para describir de manera mucho más compleja los discursos que circulan en un grupo social, estableciendo una relación entre la acción comunicativa y la construcción subjetiva e intersubjetiva de los sujetos.

Así, recurrir al enfoque cualitativo-interpretativo centrado en el mundo del discurso, permitió evidenciar los imaginarios sociales de los maestros y maestras en sus discursos, tomar las acciones como textos o discursos que pueden ser leídos, además de develar la relación entre los imaginarios instituidos, instituyentes e institucionalizados y las acciones pedagógicas en el marco del contexto institucional "la escuela" que, como parte del mundo cultural, está lleno de significaciones sociales. Por lo tanto, en esta relación, la interpretación se establece en un momento comprensivo, orientado a que la escuela y sus maestros interpreten y comprendan lo que hacen y así mismo lo resignifiquen.

11 Este instrumento es diseñado a partir de una de las metodologías de recolección de las representaciones sociales propuestas por Jean-Claude Abric en el texto "Prácticas sociales, representaciones sociales", en Prácticas sociales y representaciones, dirigido por J. C. Abric (México, D. F.: Ediciones Coyoacán, 2001). 


\title{
3. Hallazgos: Imaginarios sociales sobre infancia y práctica pedagógica
}

Los hallazgos que se presentan a continuación devienen del proceso de sistematización, análisis e interpretación que partió de reconocer la experiencia de vida y formación de los maestros, el contexto de la escuela y su institucionalidad, para luego en ese entramado cultural develar las significaciones instituidas e instituyentes sobre los niños y niñas que como dispositivos determinan la práctica pedagógica y las formas de relación y trato con ellos.

Maestros y maestras, formación y profesión: un imaginario de docente entre lo instituido y lo institucionalizado

En los relatos cortos de vida muchos docentes manifiestan haber llegado al magisterio por tradición familiar, por haber sido normalistas y, aunque no estuvieran convencidos, tomaron la decisión de convertirse en maestros ante la imposibilidad de hacer otra carrera. También afirman que, a medida que ejercieron su profesión, se fueron comprometiendo cada vez más con ella al punto de considerarla una labor importante en el desarrollo de su vida y de su familia. Esto los convierte en unos docentes preocupados por el desarrollo y las condiciones de sus estudiantes, y los lleva constantemente a buscar capacitación y a implementar estrategias pedagógicas para lograr que la propuesta institucional llegue a los niños y niñas y cumpla los fines de la educación.

\begin{abstract}
Llegué a bachillerato, algo que no se me puede olvidar del bachillerato es la normal, la planta física de la normal tiene una quebrada que le pasa por toda la mitad, es campestre allá, por decir, en esa cabaña son sextos, hermosísimo entonces donde hacer descalzos, donde volarse, donde esconderse, donde hacer lo que quisiera, era ahí en la normal ${ }^{12}$.
\end{abstract}

Pero también algunos manifiestan que siempre quisieron ser maestros y aunque sus experiencias de vida escolar fueron duras, habían decidido iniciar su labor como docentes no por tradición sino por gusto.

\begin{abstract}
Llego a la docencia de forma muy curiosa; cuando yo iba a empezar mi proceso de educación superior les dije que yo quería estudiar licenciatura en Educación Física. Entonces ellos nunca me lo permitieron porque para ellos el gremio estaba muy complicado, que era muy difícil. Mi mamá siempre ha sido docente del Distrito, pero ha tenido colegio privado también, entonces un día les faltó la profesora de preescolar y el salvavidas fui yo, entonces empecé a trabajar con ello y ahí me quedé. Ahí terminé mi carrera e hice mi especialización en Educativa. Entonces todo me llevó a lo que ellos me habían querido alejar ${ }^{13}$.
\end{abstract}

De muchos de los relatos de vida de los maestros se infiere que existe en ellos la necesidad permanente de capacitarse, de superar lo instituido de su for-

12 Relato de vida, maestra. Bogotá, D. C., 4 de junio de 2007.

13 Relato de vida, maestra. Bogotá, D. C., 25 de junio de 2007. 
mación, encontrar en la formación docente y en su experiencia los arraigos que orienten su quehacer con los niños y los jóvenes. Requiriendo no solamente de la experiencia sino de la construcción de un saber "destinado al empoderamiento del maestro como sujeto de su saber"14. Unas prácticas culturales y un saber que portan en sí unos imaginarios sociales arraigados, instituidos, que han determinado la construcción del sujeto maestro, así como la construcción de unos imaginarios acerca de la infancia, los niños y las niñas.

De manera que se puede establecer la relación entre los imaginarios sociales instituidos que hacen parte de la experiencia de vida, con los cuales llega el maestro a su formación profesional y luego a su práctica pedagógica y ese entramado pedagógico y cultural que es la escuela, la cual, desde una propuesta institucional, remueve o desestructura esas significaciones y les permite a maestros y maestras enunciar las experiencias que les ha dejado su vida escolar tanto como los conocimientos adquiridos. Así lo enuncian algunos docentes en sus relatos de vida y en la observación de clase, al considerar importantes en el desarrollo de su actividad factores como:

\begin{abstract}
La memoria no debe ser una herramienta como método de enseñanza.
El llevar los niños desde grados anteriores es una fortaleza, por tal motivo conoce y sabe a qué niño le debe hacer refuerzo.

El ser amigable y la forma de dialogar con el niño, sin dejar de lado un tono de voz alto.

El mejor proyecto es conseguir que los niños hagan las cosas por gusto y sobre todo siempre en busca de un aprendizaje.

El vínculo con la escuela es sobre todo para leer y escribir.

Las actividades lúdicas donde la naturaleza interceda son gratificantes para el niño.

Es importante conocer y respetar las formas de aprender de cada niño ${ }^{15}$.
\end{abstract}

Entre los maestros existe la preocupación de hacerles llegar su propuesta pedagógica a los niños y las niñas $\mathrm{y}$, aunque muchas de sus estrategias no logren impactar de la forma deseada, ya sea por la influencia de factores externos o por situaciones propias de la dinámica institucional, ellos continúan desarrollando su trabajo teniendo en cuenta que son dueños de unos instrumentos de trabajo y de un saber.

De igual forma se puede leer que la preocupación constante de los maestros y las maestras es la formación de niños, niñas y jóvenes para la vida, que sean líderes. Para algunos su papel es la transmisión de la cultura letrada y por lo tanto consideran fundamental no solo el método sino el aplicar a su quehacer un saber pedagógico, es decir, no solo la instrumentalización sino el dominio de unos saberes que los ubican en el rol de sujetos de la enseñanza.

Estas preocupaciones también se hacen explícitas en los textos de reconocidos pedagogos.

14 Óscar Saldarriaga, Del oficio de Maestro. Prácticas y teorías de la pedagogía moderna en Colombia (Bogotá: Editorial Magisterio, 2002), 245.

15 Relatos de vida y observación en el aula, abril y julio de 2007. 
Debemos también hacer una distinción entre los sujetos de la enseñanza. Existen dos sujetos de la enseñanza. Por una parte, aquel que se relaciona con las ciencias o con los saberes a partir de un método, es decir, el maestro, porque el ejercicio de su saber está completamente fetichizado desde una concepción instrumental del método de enseñanza. Socialmente se reconoce como maestro a quien se supone como muy claro, muy sencillo y muy simple para exponer, porque tiene como herramienta fundamental el método. Mientras más desarraigado del saber está el maestro en una formación social y mientras mayor sea su desarraigo cultural, más se enfatiza en su oficio metodológico; de esto último tenemos una muestra muy clara en la forma como existe la pedagogía de hoy día en las Facultades de Educación. Pero existe por otra parte, otro sujeto que también enseña y al que se llama docente. Este sujeto de la enseñanza es reconocido como tal, no a partir del método de enseñanza, sino del saber que transmite, él puede ser profesor de matemáticas, profesor de física, profesor de filosofía, profesor de psicología, es decir su estatuto como docente en la sociedad se le reconoce desde otro saber que no es la pedagogía. Sin embargo, los dos sujetos enseñan, pero la diferencia entre esos dos sujetos es una resultante de la forma de institucionalización y de la adecuación social de los saberes, mas no es una distinción que se derive de la naturaleza de la pedagogía ${ }^{16}$.

Los maestros consideran que, para realizar una buena labor educativa, tanto la escuela, como el entorno, la familia y los docentes deben, entre muchas otras cosas, propender por:

El poder brindarles un espacio amplio, muchas zonas verdes para que puedan aprender relacionándose con su entorno.

La honestidad y la libertad, dos principios que la escuela debe tener.

El padre debe acompañar y supervisar las tareas con sus hijos.

El colegio siempre debe aportar para que los niños sean líderes.

La relación y el compañerismo en una institución son importantes, porque cada profesor le puede aportar a su colega.

El maltrato no tiene por qué darse en la relación con los niños.

El colegio y sus docentes no deben ser un archipiélago, cada uno en su isla, el trabajo en grupo es importante y necesario ${ }^{17}$.

Aquí nuevamente aparece el imaginario social instituido de infancia, de niño y niña, que considera a la infancia como la etapa de vida que hay que proteger y a los niños como personas que deben ser preservadas del ocio y la perversión del mundo adulto. Al igual que la necesidad de orientar al niño para que sea buen ciudadano y se forme para la vida, por eso muchos de ellos consideran que el objetivo de su quehacer es:

Yo creo que es ayudar a formar los futuros ciudadanos, que aprendan hábitos y conocimientos que le sirvan para la vida.

16 Martín Barbero citado por Saldarriaga, op. cit., 33.

17 Relatos de vida y observación en el aula, abril y julio de 2007. 
Yo creo que es formar para la vida, lo que los niños aprenden en la escuela les debe servir para la vida, para su experiencia.

Educar, formar valores y hábitos para la vida es ayudar a que los niños y las niñas tengan herramientas para procesar bien ese cúmulo de información que el mundo les brinda y puedan utilizar para su futuro.

El objetivo fundamental de mi práctica pedagógica, más que una formación académica, es una formación integral. Más que meterle conocimientos, conceptos y temas, es más la formación de hábitos, especialmente con estos chiquiticos que uno tiene en primero. (...) Es como encaminar todo esto para que ellos sean personitas más grandes y autónomas. ${ }^{18}$

Desde estas significaciones sociales de su quehacer, los maestros y maestras de la institución promueven una idea de infancia desde la pedagogía como punto de partida y llegada. Los niños y las niñas escolarizados son el punto de preocupación del quehacer docente, "formar para la vida, formar para ser buenos ciudadanos, enseñar a manejar y a utilizar" son expresiones que, mediadas por una intensión pedagógica, hacen del niño y el joven personas que deben ser orientadas desde los procesos de enseñanza y aprendizaje. "La pedagogía, en tanto producción discursiva destina a normar y explicar la producción de saberes en el ámbito educativo-escolar, dedica sus esfuerzos a hacer de esos pequeños 'futuros hombres de provecho', o 'adaptados a la sociedad de manera creativa' o 'sujetos críticos y transformadores', etc."19.

Desde esta perspectiva, los maestros y maestras establecen el sentido de su acción en el hecho de intervenir para educar y reeducar en el espacio de la escuela, así como la pedagogía encuentra su razón de ser para participar en la formación de los seres humanos.

\section{Dualismos: imaginarios instituidos-institucionales e instituyentes sobre niñas y niños escolares}

Los maestros y maestras han construido un imaginario de niño y niña desde su experiencia infantil, pero también desde la forma como se han relacionado con los niños y las niñas. Significaciones imaginarias que se constituyen desde lo instituido y lo institucionalizado a través de su rol de agentes educadores. Así encontramos que algunos maestros tienen imágenes de niño y niña como:

ternura, amor, cuidado; ser sincero y especial; seres inocentes que viven experiencias nuevas; personitas que necesitan cuidado, amor, respeto y protección; proyecto en construcción; personita especial que tiene un mundo ideal; la inocencia, la ternura y la verdad; la felicidad a partir de la inocencia; ser humano que comienza $a^{20}$.

18 Relatos de vida de Maestros, junio - julio 2007

19 Mariano Narodowsky, Infancia y poder. La conformación de la pedagogía moderna (Buenos Aires: Editorial Aique, 1994), 24.

20 Sistematización entrevista estructurada a maestros, mayo de 2007. 
Estas imágenes son consecuentes con la idea o la concepción que tienen de niño y niña, cuando en la entrevista se pregunta ¿quién es para usted un niño o niña?, ante lo cual algunos enuncian:

- Pensaba que es un cuaderno donde todo el mundo escribe, algunos hasta le arrancan hasta las hojas; yo pienso que cada persona le da a cada niño... le escribe algo en ese cuaderno algunos con letra muy bonita, pero otros tachan, se le hace la orejita del perro. Si algunos lo que escriben hay... Yo a veces hasta preferiría revisar sin escribir para no poner más trabas. Pero también pensaba en la inocencia natural, en la cual se pueden envolver ellos mismos sin tanto peso cultural. No sé si ahí apunte la palabra que dice que el niño nace muy bueno pero la misma sociedad la corrompe, y es verdad, a los niños los matamos, no sé si los maestros, los papás, la sociedad, todo el mundo, pero el niño es la persona más inocente. Un estudiante es una personita que aprende en la escuela.

- Para mí un niño es un ser curioso, un ser ávido de conocimiento; acudiendo a la tecnología lo comparo como la cámara de vídeo, filma todo, filma todo, recibe todo, él tiene imágenes, lo que ve, lo que siente, lo que oye, todo lo graba, el buen ejemplo, el mal ejemplo, las buenas palabras, las malas palabras, todo, todo, todo lo graba. Un estudiante es un niño que se encuentra matriculado en una institución escolar y por tanto tiene unas funciones y unas acciones particulares que cumplir ${ }^{21}$.

Ideas e imágenes que hacen parte de las significaciones imaginarias sociales de un grupo de maestros que ha construido y explicitado las características y las condiciones de los niños y las niñas desde un imaginario instituido y desde su experiencia de vida. Por tanto, como imágenes e ideas, se constituyen en saberes implícitos o cotidianos que no solamente existen en las mentes de los que los representan, sino que son imágenes e ideas desde las cuales los sujetos crean su mundo, promueven procesos de relaciones e interacciones, que además determinan sus acciones, en este caso, pedagógicas.

Esta red simbólica que hace parte de las significaciones imaginarias y constituye los imaginarios sociales compartidos en un momento histórico determinado, va desde la percepción inicial de la vida infantil y su experiencia hasta la vida en la escuela. De acuerdo con las imágenes y los textos de los discursos de los maestros se pueden determinar varias significaciones imaginarias sociales que constituyen un imaginario social instituido de niño y niña que portan los maestros.

Los niños y las niñas incompletos, proyección del futuro hombre

Cuando los maestros se refieren al niño y la niña como "personita" se percibe la presencia fuerte de unas imágenes que dan cuenta de un imaginario instituido., El diminutivo hace referencia a un ser menor, pequeño (a) de cuerpo, inmaduro. También puede tener el significado peyorativo del no reconocimiento del niño y la niña como sujetos. Elementos de un imaginario en el cual el niño fue considerado por mucho tiempo un ser irrelevante hasta tanto no cumpliera los

21 Entrevista a maestro, Bogotá, 30 de marzo de 2007. 
siete u ocho años de edad, cuando se pensaba que adquiría ya una "consciencia" que le permitía tener razón y en consecuencia un espacio moderado de opinión, pero siempre bajo la tutela y decisión final del adulto.

Encontramos la idea de niños y niñas asociada a sentimientos como "ternura", "felicidad", "amor", "libertad" y "desarrollo", ideas de una conceptualización respecto a la niñez tal vez aprendida en su experiencia como madres, padres o hermanos mayores. Representación en la que se utilizan adjetivos y calificativos que no reconocen al niño en su complejidad como ser, o configuran la idea de niños y niñas como seres incompletos. Imaginarios que obedecen al ideal de niñez que se configuró en la sociedad colombiana de acuerdo con la pedagogía de finales del siglo xIX y comienzos del $\mathrm{xx}$, orientada por concepciones religiosas que veían a los niños como "demoníacos o divinos", "ángeles o demonios", "flor inmaculada", "rocío de la mañana", "árbol que hay que cuidar e impedir que se tuerza", "tabula rasa en la que hay que imprimir las bondades del mundo adulto ${ }^{22}$.

\section{Los niños y las niñas objeto de intervención}

A pesar de lo anterior, en los discursos e imágenes se observa la incorporación de elementos diferentes que provienen de la formación académica de maestras y maestros, y a las frases con las que describen a los niños y las niñas se adicionan otros términos como "seres en desarrollo", "seres humanos valiosos", "futuro de la humanidad", y en general, seres que requieren ser educados y protegidos.

Discursos en los cuales se hace evidente un acercamiento a la modificación de los imaginarios sociales acerca de los niños y las niñas y que se puede rastrear en el discurso pedagógico de mediados del siglo xx, como lo sostienen Cecilia Muñoz y Ximena Pachón:

Con la transición de lo religioso-militar, a lo político-administrativo, la niñez inicialmente a cargo de las instituciones religiosas, pasó a manos de las instituciones laicas() La familia y la escuela se convirtieron en modelos de funcionamiento y reemplazaron al convento y al cuartel. Las antiguas instituciones de protección y rehabilitación de tipo autoritario y masivo, se reemplazaron por las escuelas hogar. Aquellas normas de crianza que recordaban los diez mandamientos fueron reemplazadas por nuevas reglas que recordaban los reglamentos escolares... lo cual hizo que lo demoníaco y divino en los niños fuera reemplazado por referencias a las características y cualidades de los niños y las niñas y (...)un reconocimiento a la vida emocional del bebé (...)"23.

Desde estas enunciaciones que son contrastadas con las ideas, imágenes, en suma, con las significaciones imaginarias que portan los maestros, se puede percibir claramente la amalgama que constituye los imaginarios sociales que han ido construyendo, en donde confluyen un imaginario constituido a partir de su experiencia como niños o niñas y un imaginario institucionalizado, construi-

22 María Victoria Alzate, La Infancia: Concepciones y Perspectivas (Pereira, Colombia: Editorial Papiro, 2003).

23 Cecilia Muñoz y Ximena Pachón, La niñez en el siglo xx (Santafé de Bogotá: Editorial Planeta, 1996), 330. 
do desde su formación como maestros. Haciendo un análisis del discurso, en la expresión "personita", conjugada con la idea de "responsabilidad social", se puede ver, disimulada, la imagen de los niños y las niñas como seres humanos frágiles ante el adulto. Estas ideas señalan una relación de poder, de autoridad y de dominio del adulto sobre el niño, situación que pone al niño en estado de vulnerabilidad, expresión que hace un llamado de atención para que el niño sea protegido y cuidado.

Los niños y las niñas, seres en formación: una idea de educación

Cuando maestros y maestras se refieren a los niños y a las niñas como "seres en formación" se evidencia un imaginario que ha hecho parte de la tradición pedagógica y educativa colombiana, en la cual se pensaba que los niños y las niñas eran seres incompletos que había que civilizar, formar; que eran seres inmaduros a los cuales había que llenar de conocimiento, valores y, en consecuencia, deberían completar un proceso de instrucción.

Un imaginario histórico social que piensa, siente y evidencia al niño y a la niña como objetos de la pedagogía, en donde se consideraban "como ser maleable e imperfecto física, intelectual y moralmente, además de irreflexivo y frágil". Esta representación de los niños y las niñas, como seres en formación es posible que tenga su origen en la experiencia personal de cada maestro y maestra, pues cuando se les pregunta en la entrevista para el relato de vida, ¿qué no repetirían de su vivencia en su práctica pedagógica?, enuncian "las clases aburridas", "las exigencias de los maestros", "las formas de enseñanza, "la soledad", "el castigo y el regaño".

De igual forma, lo que se evidencia al considerar los niños y las niñas como seres en formación es el imaginario educativo presente en la sociedad colombiana durante el siglo xix y parte del xx; el cual se puede referenciar: "La educación, ideal supremo (...) debe mirar el perfeccionamiento de todo ser, así como en lo físico e intelectual, como en lo moral y religioso, individual y social(...) Educar es sacar al hombre... de la debilidad a la firmeza... de la ignorancia al saber, de la bajeza a la dignidad..." ${ }^{24}$.

Sin embargo, en las imágenes que emergen en la sistematización de la encuesta a maestros, otros docentes refieren a los niños y las niñas como: "Personas con su propio mundo, con habilidades, capacidades e intereses"; "personitas emprendedoras, inquietas por descubrir"; "seres con inteligencia que se desenvuelven en el mundo"; "personas con capacidad de explorar el mundo".

Desde un enfoque contemporáneo de la educación, las imágenes y expresiones de los maestros como "personas con su propio mundo, seres humanos como un cúmulo de experiencias, personas con capacidades, seres en formación", tienen una connotación diferente y es posible que refieran a la capacidad humana de aprender constantemente y estar en proceso de renovación permanente.

El niño y la niña desde las asociaciones con la práctica pedagógica

24 Alzate, op. cit., 60. 
Como se expresó en el marco teórico de este estudio, la práctica pedagógica se sitúa como una práctica social desarrollada por un grupo particular de sujetos, lo cual la determina como una acción pedagógica y se sustenta en las teorías y los enfoques pedagógicos asumidos por los maestros y maestras en su formación.

Así, los maestros y maestras construyen significaciones imaginarias de niño y niña asociadas a su labor pedagógica, lo que se pudo evidenciar en las asociaciones verbales, donde en un primer nivel de asociación, los maestros asocian los niños y las niñas a su labor pedagógica con el juego, el aprendizaje, la protección, nutrición y los valores. Asociaciones que son manifestación de un imaginario instituido donde los niños y las niñas son objeto de protección, cuidado, que deben aprender y asimilar los valores de la sociedad para llegar a ser buenos ciudadanos.

Evidenciar el juego como una asociación a su labor pedagógica en relación con los niños y las niñas, muy probablemente indica el juego como la actividad preferida de la infancia o el juego como una posibilidad de aprendizaje; sin embargo, esto no es claro pues en la asociación no se establece la relación entre juego y aprendizaje, lo cual muestra un imaginario instituido recurrente en los docentes que parte no solo de su formación sino de su experiencia personal.

En un segundo nivel de asociación se encuentran expresiones que relacionan a los niños y las niñas a la labor pedagógica con conocimiento, motivación, formación académica, participación, enseñanza, aprendizaje, valores asociados a la formación, a la preparación y el juego asociado a la enseñanza. Aquí fluyen unas significaciones imaginarias más relacionadas con los objetivos y los propósitos de la práctica pedagógica en el ámbito escolar, en donde la preocupación por el aprendizaje de los niños y la formación en valores surge como el objeto fundamental de su acción pedagógica.

Esto pone en evidencia cómo desde las significaciones imaginarias acerca de los niños, los maestros (as) llenan de sentido y dan significado a su práctica pedagógica que se orientaría desde discursos que en Colombia existen a partir de 1914, en el marco del modelo de Escuela Activa, el cual tenía como fin lograr la formación, la protección, el cuidado y el aprendizaje de los niños, las niñas y los jóvenes, el cual instituye una práctica pedagógica orientada a dirigir y controlar el trabajo de los niños y las niñas, lo que se puede observar también cuando ellos enuncian en las entrevistas que:

Considero fundamental ayudar a los niños a desarrollar su proyecto de vida. Los niños están asociados al juego y la creatividad, pero en el aula de clase estas actividades deben ser orientadas para que se formen como personas y puedan aprender y desarrollar el conocimiento y su vida ${ }^{25}$.

De igual forma en las observaciones de clase se evidencian expresiones como:

25 Entrevista a maestra, Bogotá, 2 de julio de 2007. 
Respeten, no sean cansones, pongan atención.

Señorita, señor, pimpollos, chiquitos, Pablito.

Comprométanse, que ustedes son niños de tercero y el hecho de tratar de mantener permanentemente al niño ocupado. Debe existir una mano dura que reprenda a los niños, ya que ni los padres se interesan por ellos, este es un curso muy pesado y todos los profesores lo dicen.

Estas formas de comunicación en el aula y las relaciones que se establecen en ella denotan un imaginario social instituido en el cual el niño y la niña deben ser reprendidos, cuidados y protegidos, son considerados como menores de edad y, a su vez, se les exige un comportamiento de adultos promoviendo que dejen los comportamientos de niños y asuman las formas de comportarse de los adultos. Al igual que se puede evidenciar un imaginario en el cual el niño es una personita inacaba que requiere permanente control y dirección por parte del adulto.

Este imaginario de niño y niña que presentan los maestros y maestras es un imaginario atravesado por las pautas de crianza, por sus experiencias como normalistas o pertenecientes a comunidades religiosas, los niños son personas que deben formarse, se siente la necesidad de construirlos, de ayudarlos y de protegerlos.

\section{Práctica pedagógica resignificada: Espacio para la emergencia de un imagi- nario instituyente sobre niño y niña}

En el marco de la propuesta pedagógica de las instituciones educativas (escuela) muchas de las significaciones de los maestros y maestras se deconstruyen y se configuran como significaciones instituyentes, en tanto estas propuestas pedagógicas se configuran en el marco de lo enunciado y ordenado por la Ley General de Educación (Ley 115/94), así como en el marco de enfoques pedagógicos novedosos como el aprendizaje significativo o la enseñanza para la comprensión, entre otros, se han orientado las prácticas pedagógicas teniendo como principios del aprendizaje el pleno desarrollo, la formación integral del niño y la niña, tanto como la formación ciudadana, lo cual ha ido instaurando en la escuela y en la sociedad unas significaciones imaginarias sobre la infancia, los niños y las niñas como sujetos de derecho, agentes de política y seres humanos con potencia, capaces de participar en la construcción de su experiencia.

La apropiación de estas políticas y nuevos enfoques pedagógicos por parte de los maestros ha demandado en las escuelas la adopción de estrategias como grupos de discusión, talleres y seminarios de formación que tocan, entre otros temas, las concepciones, ideas o representaciones que los maestros tienen de los niños y niñas. En el marco de estos ejercicios se puede evidenciar que allí emerge en el discurso del maestro o maestra, bajo la incidencia de unos discursos teórico-pedagógicos, nuevas significaciones que podemos decir se plantean como instituyentes. Así los niños y niñas son considerados como: 
Ser sensible, pensante, con posibilidades, con capacidades de desarrollar su conocimiento, sus experiencias de vida desde la diversidad. Persona integral entre los 0 y 12 años, con características, intereses y necesidades propias, con disposición para aprender, inquieto por conocer el mundo que lo rodea. Persona con ciertas características piscobiológicas con habilidades, necesidades, expectativas, aspiraciones, deseos e intereses en constante evolución ${ }^{26}$.

En estas declaraciones de los maestros, construidas desde la propuesta pedagógica de la institución, se pude leer que dentro de la escuela se logra instituir a los sujetos como creadores de unas relaciones de comunicación y de un contexto cultural, además de pensar la escuela y la acción pedagógica como una permanente relación entre los sujetos y el mundo social. Relación que construye la complejidad de la institución educativa y el mundo de la vida, llenando de sentido la acción, el pensamiento y los sentimientos.

Una complejidad que reconoce a los niños y los instituye como sujetos sociales, desde su diversidad y multiexpresividad, inmersos en una cultura rebozada de símbolos y, por lo tanto, creadora de sentido y de trascendencia para los sujetos que en ella desarrollan su existencia.

Desde esta perspectiva, cuando los maestros y maestras son convocados desde una institución como la escuela, en torno a una nueva propuesta de formas de trabajo, comienzan un proceso de resignificación de sus ideas, conceptos y formas de hacer, en suma, de los imaginarios sociales que como "magma" articulan y dan sentido a los pensamientos y las acciones. Podemos entenderlos como imaginarios instituyentes pues instauran unas nuevas relaciones, nuevas significaciones y nuevas formas de práctica pedagógica.

\section{CONCLUSIÓN}

El estudio da cuenta de las significaciones imaginarias sociales y la constitución de los imaginarios sociales de infancia, niño y niña con los que los maestros y maestras del colegio Santa Librada estructuran y significan su práctica pedagógica, se logra evidenciar esa dialéctica permanente entre el sujeto y la escuela como institución de una sociedad; además, como los imaginarios sociales o son diversos, se elaboró un tejido (magma) que da sentido al quehacer del docente que se mueve permanentemente entre lo instituido, lo institucionalizado, para crear lo instituyente.

El estudio permitió develar esa amalgama de significaciones imaginarias e imaginarios que constituyen la escuela como una necesidad de la comunidad para "proteger a los niños y niñas" en estas zonas de Bogotá a partir de un proceso de institucionalización que define la educación de la infancia en la cual se pueden leer las significaciones sociales que marcan un imaginario instituido de infancia, niño y niña como "la infancia debe ser protegida para su culturización

26 Grupo de Discusión, 30 de agosto de 2007. 
y socialización". Y los niños son escolares y alumnos, obedeciendo con ello a la concepción de la infancia desde la pedagogía moderna.

El estudio evidenció la presencia del dualismo en la constitución de imaginarios sociales sobre infancia de los maestros, que se logra evidenciar en las significaciones imaginarias que expresan los maestros y maestras como la dialéctica en la que se constituyen los imaginarios sociales de un grupo humano.

Se demuestran las discontinuidades y continuidades en el proceso de constitución de los imaginarios sociales y las significaciones imaginarias sociales donde se entrecruzan unos imaginarios sociales atravesados no solo por la experiencia del maestro o la maestra como niño o niña, sino también por su formación académica, que de una manera u otra modifican sus significaciones de educación e incorporan elementos nuevos a las ideas de niño, niña e infancia.

Estas significaciones dualistas poseen, a su vez, una influencia enorme en la escuela instituida como base de las clasificaciones que ubican a los niños como "buenos o malos", "inteligentes o lentos", "predilectos o indeseables" e incluso, apoyados en lenguajes técnicos, "normales e hiperactivos". Dichas significaciones dualistas son recurrentes en la práctica pedagógica.

Se puede concluir que es desde las significaciones imaginarias que los maestros dan sentido a su quehacer y promueven una idea de infancia desde la pedagogía, como punto de partida y llegada. Los niños y las niñas escolarizados son el punto de preocupación del quehacer docente, "formar para la vida, formar para ser buenos ciudadanos, enseñar a manejar y a utilizar" son expresiones que, mediadas por una intensión pedagógica, hacen del niño personas que deben ser orientadas desde los procesos enseñanza y aprendizaje.

Se puede inferir que los imaginarios sociales de niño y niña que portan los maestros del colegio Santa Librada se instituyen con el entretejido de grupos poderosos de significaciones imaginarias, como son: un primer grupo que dibuja una concepción de niño(a) que arrastra viejas tradiciones escolares, religiosas y sociales que mantienen su vigencia entre algunos maestros y maestras de la actualidad. Y un segundo grupo de significaciones imaginarias que se dibujan entre lo instituido y lo institucionalizado (desde la formación académica de los maestros) que sostienen una concepción cientificista de dibujo constructivista. $Y$ un tercer grupo más pequeño de significaciones más radicales, también institucionales, que ven al niño o niña de manera más compleja.

En este mismo sentido, se hace evidente la influencia de la formación del docente, en donde la recontextualización de los discursos pedagógicos contribuye a encontrar los sentidos y significados otorgados a los niños y las niñas, mostrando la construcción de un discurso alternativo sobre la infancia, los niños y las niñas, en la cual se encuentra la presencia del niño o la niña como sujeto de la educación.

De otra parte, el estudio logra establecer cómo, desde una propuesta institucional que se promueve como modificación de las prácticas pedagógicas, se pueden modificar las significaciones imaginarias y movilizar la institución de 
un imaginario instituyente sobre infancia que permite y da sentido a la acción y el desarrollo de prácticas pedagógicas que emergen como alternativas.

Lo anterior implica que los imaginarios sociales constituidos por ese magma de significaciones sociales que emplean todo tipo de producciones sociales para sobrevivir y desde las cuales se otorgar sentido a la acción y se arraigan en las prácticas sociales, para este caso la práctica pedagógica, se tejen y entretejen, se construyen y deconstruyen en una relación permanente entre lo instituido, lo institucionalizado y lo instituyente (como poder creador). Pero además, como construcciones históricas y culturales, se modifican en el complejo mundo social desde lo instituido hacia lo instituyente, pasando por lo institucionalizado.

Así mismo la investigación logra poner en evidencia que, en la institución educativa bogotana, lo instituyente surge de lo institucionalizado, es decir, que emerge desde un mandato de ley o una propuesta pedagógica institucional. Un imaginario institucionalizado que puede leerse en su origen como la necesidad de la sociedad de modernizar sus instituciones.

\section{FUENTES}

Relatos de vida y observación en el aula, abril y julio de 2007.

Relatos de vida de Maestros, junio - julio 2007.

Relato de vida, maestra. Bogotá, D. C., 4 de junio de 2007.

Relato de vida, maestra. Bogotá, D. C., 25 de junio de 2007

Entrevista a maestro, Bogotá, 30 de marzo de 2007.

Entrevista a maestra, Bogotá, 2 de julio de 2007.

Sistematización entrevista estructurada a maestros, mayo de 2007.

\section{REFERENCIAS}

Abric, Jean-Claude. "Prácticas sociales, y representaciones sociales". En Prácticas sociales y representaciones. Dirigido por J.-C. Abric. México, D. F.: Ediciones Coyoacán, 2001.

Alzate, María Victoria. La Infancia: Concepciones y Perspectivas. Pereira: Editorial Papiro, 2003.

Anzaldúa Arce, Raúl Enrique. "Lo imaginario como significación y sentido". En Imaginario social: creación de sentido. Coordinado por Raúl Enrique Anzaldúa Arce. México: Universidad Pedagógica Nacional, 2012.

Baczko, Bronislaw. Los imaginarios sociales: Memorias y esperanzas colectivas. Buenos Aires: Editorial Nueva Visión, 1991.

Bocanegra Acosta, Elsa María. “Del encierro al paraíso. Imaginarios dominantes en la escuela colombiana contemporánea: una mirada desde las escuelas de Bogotá". Revista Latinoamericana de Ciencias Sociales, Niñez y Juventud, 6, n. ${ }^{\circ} 1$ (2008): 319-346.

Carretero, Ángel. "Postmodernidad e imaginario: una aproximación teórica". A Parte Rei, n. ${ }^{\circ} 21$. Acceso en marzo de 2016. serbal.pntic.mec.es/ cmunoz11/carretero26.pdf.

Muñoz, Cecilia y Ximena Pachón. La niñez del siglo xx. Santafé de Bogotá: Editorial Planeta, 1996.

Narodowsky. Mariano. Infancia y poder. La conformación de la pedagogía moderna. Buenos Aires: Editorial Aique, 1994.

Palacios Mena Nancy, "Transformación y crisis de la escuela: algunas reflexiones sobre el caso colombiano" Revista Historia de la Educación Latinoamericana, vol. 15, n. ${ }^{\circ} 21$ (2013): 335-376.

Saldarriaga, Óscar. El oficio de Maestro: Prácticas y teorías de la pedagogía moderna en Colombia. Bogotá: Editorial Magisterio, 2002. 


\section{en la práctica pedagógica de una escuela bogotana}

Soto Arango, Diana Elvira. “Legislación e imaginarios sociales en el escalafón y los salarios de los educadores de primaria en Colombia, 1952-1994". Revista Historia de la Educación Latinoamericana, vol.15, n. ${ }^{\circ} 21$ (2013): 229-262.

Torres Cruz, Doris Liliana. "El papel de la escuela en la construcción de la nacionalidad. Una aproximación a la escuela elemental, 1900 a 1930". Revista Historia de la Educación Latinoamerica$n a, \mathrm{n}^{\circ} 13,(2009): 213-240$.

Zemelman, Hugo. Determinismos y alternativas en las ciencias sociales de América Latina Caracas: Nueva Sociedad, 2000.

\section{Cómo citar:}

Triviño R., Ana Virginia. "Imaginarios sociales de infancia y su incidencia en la práctica pedagógica de una escuela bogotana" Revista Historia de la Educación Latinoamericana. Vol. 20 No. 31 (2018): 47-69

DOI: $10.19053 / 01227238.8538$ 